\title{
EM QUE SÉCULO, AFINAL, SE ENCONTRA O CORPO DO ATOR GAÚCHO?
}

O homem sempre teve muita dificuldade em ver claramente e sem preconceitos o seu próprio corpo. Desde Platão, século V a.C., a dicotomia corpo-mente já aparecia e, de maneira geral, sempre houve uma tendência entre os filósofos em explicar o homem não como uma unidade integral, mas como composto de duas partes diferentes e separadas: o corpo (matéria) e a alma (espiritual e consciente). O chamado dualismo psicofísico, ou seja, a dupla realidade da consciência separada do corpo.

O teatro, como bem diz Caio César Próchno,

"se esboça ou se esboçou sempre como uma resistência ao status quo, talvez uma advertência, um dizer-não a um todo estabelecido, estruturado, instituído" (1999, p. 35).

$E$, embora tenha acompanhado este dualismo por um certo período (séculos XVIII com o final da tradição da Commedia dell'Arte até final do século XIX e o naturalismo), não tardou a surgirem estudiosos, pensadores de teatro e dança a se rebelarem e tentarem reverter este conceito. O final do século XIX, inaugurou esse período de 'rebeldia' nas Artes

Cênicas Ocidentais. Tanto no Teatro, quanto na Dança, surgiram algumas figuras que iniciaram uma transformação 'no palco'. Um período de investigações do próprio passado do teatro, de busca do verdadeiro papel do ator, um período que iniciou, segundo Barba e Savarese, a Nostalgia1 que predominou durante todo o século $\mathrm{XX}$, no campo teatral.

Com a reaproximação entre dança e teatro, o corpo volta a ter a importância que Ihe havia sido retirada quando da divisão ator bailarino. $O$ teatro predominantemente textual passa a dar lugar novamente à teatralidade, ao corpo expressivo reclamado por Artaud e trabalhado por Copeau, à plasticidade e ao grotesco procurados por Meyerhold, às ações físicas de Stanislavski, ao corpo revolucionário e político de Brecht. Enfim, a estas alturas do século $X X I$ já poderíamos dizer que o corpo do ator é objeto de cuidado e 
que vem sendo levado a sério, sendo ele seu único instrumento de trabalho. Mas, infelizmente, isto não é bem verdade.

Ao longo da minha vivência teatral, pude perceber que a preocupação com a preparação corporal varia enormemente de ator2para ator: muitos atores não costumam se aquecer antes de um ensaio ou apresentação. Alguns até usam um método de 'aquecimento' muito difundido pelos mais antigos: o conhaque! Já, em contrapartida, outros utilizam treinamentos de esforço físico e exaustão que, levados ao extremo ou mal executados, podem resultar em estresse físico e, conseqüentemente, às lesões.

Durante o curso de Educação Física, comecei a me preocupar com a questão da preparação e do aquecimento corporal. Ao compreender os processos que acontecem no corpo desde o estímulo elétrico até a contração e o relaxamento; equilíbrio, postura e a imensa importância da coluna vertebral e seus sistemas nervosos, dei-me conta de como nós, atores e bailarinos, costumamos realizar (quando realizamos), salvo honrosas exceções, o aquecimento corporal de uma maneira despretensiosa ou como reprodução mecânica sem sabermos, muitas vezes, o objetivo de cada exercício e a real importância de nos exercitarmos com regularidade e consciência.

“Definimos o artista cênico como aquele cuja obra não é um objeto exterior a ele, mas está nele próprio. Em outras palavras, é aquele que traz em seu próprio corpo o resultado de sua arte" (Strazacappa, 1999, p.163). Esse corpo, portanto, deve ser tratado com muito cuidado e respeito para que, através dele, consiga encantar, emocionar e surpreender.

Jean-Jacques Roubine nos ensina que:

"Costuma-se esquecer facilmente que o palco deveria ser o lugar mágico onde, a exemplo do teatro japonês, o velho representaria meninas ou a atriz faria o papel dos velhos, num perfeito domínio da sua respectiva corporalidade." (1987, p. 49)

Com base nesses questionamentos, entrevistei alguns colegas com 0 objetivo de verificar como os atores gaúchos vêm trabalhando o corpo e que preocupações demonstram na preparação e manutenção da sua saúde corporal.

Escolhi 11 atores atuantes do teatro gaúcho atual, para os quais foram feitas de 6 a 8 perguntas gravadas que variavam apenas conforme suas 
respostas iniciais e o desenrolar da entrevista. O critério de escolha desses atores obedeceu ao fato de serem eles representantes de variadas vertentes ou linhas de trabalho diferenciadas entre si que possibilitasse uma análise mais ampla e não direcionada.

\section{Roteiro de entrevistas para atores e atrizes:}

1- O que te vem à mente quando se fala que "O CORPO DO ATOR É SEU PRÓPRIO INSTRUMENTO DE TRABALHO”?

2- Tu realizas algum tipo de aquecimento antes de uma apresentação ou ensaio?

3- Tens um repertório de exercícios fixo ou mudas conforme a exigência do trabalho?

(OU: tens consciência da utilidade de cada exercício ou fazes porque estás acostumado (a) a eles?)

4- Que preocupações tu tens, para a manutenção da saúde corporal, no teu dia a dia?

5- Tu achas que o teu 'instrumento' está suficientemente 'afinado' para o tipo de teatro que tu fazes?

6- Já tiveste algum tipo de lesão por esforço excessivo ou mau uso do corpo?

7- O que te levaria (ou te leva) a não se preparar para uma apresentação?

Com base nas respostas dos entrevistados, faço algumas considerações e impressões, guiada pelas seguintes questões:

- Como ainda permanece o conceito de separação corpo-mente ou corpo-voz entre os nossos atores.

- Ao realizar ou não a preparação corporal, quanto da individualidade é respeitada e quanto o grupo pode influenciar nessa decisão.

- Como o conceito holístico de manutenção da saúde corporal e consciência corporal se estabelece dentro e fora do palco.

- A possibilidade, ou não, de se estabelecer um paralelo entre o preparo corporal (ou o não preparo corporal) e o resultado obtido em cena. 


\section{O Corpo ainda dividido}

Vários atores entrevistados ainda têm muito presente a dicotomia corpomente e corpo-voz, como se o seu corpo não fosse uno, integral. Sem falar na separação, ainda bastante arraigada entre a maioria dos atores gaúchos, do conceito ator-bailarino.

Quando questionados sobre o corpo ser o único instrumento de trabalho do ator ou sobre a preparação corporal, poucos falam em aquecimento vocal. Alguns até confessam nunca terem se preocupado com a voz até terem de interromper uma temporada ou turnê por causa de problemas vocais.

Percebe-se também, com facilidade, que os atores que confessam não se aquecerem antes de um espetáculo ou ensaio são os que seguem uma linha de teatro que utiliza técnicas tradicionais de representação. Enquanto, ao contrário, os atores que afirmam ser fundamental o aquecimento e a preparação prévia, seguem a linha teatral que utiliza técnicas extracotidianas de representação. Segundo Barba (1994, pág 31),

\footnotetext{
"as técnicas cotidianas do corpo são em geral caracterizadas pelo princípio do esforço mínimo, ou seja, alcançar o rendimento máximo com o mínimo uso de energia. As técnicas extracotidianas baseiamse, pelo contrário, no esbanjamento de energia. (...) o princípio do uso máximo de energia para um resultado mínimo."
}

É interessante, por exemplo, ouvir de um ator ao ser questionado sobre o que o leva a não se preparar para uma apresentação ou ensaio, que ele nunca sentiu necessidade de se preparar fisicamente. E se justifica dizendo que o tipo de teatro que ele faz não é um teatro físico, um 'teatro moderno' que exija uma preparação física maior. E completa, chamando de linha Stanislavskiana, o teatro textual que ele faz.

A menção ao nome Stanislaviski remete, erroneamente, a um teatro mais 'intelectual' ou naturalista, portanto não-corporal. Não vamos nos aprofundar aqui no quanto, ao longo dos anos, os estudos de Stanislavski foram mal interpretados e se tornaram um sinônimo de teatro em que se mergulha no íntimo do personagem de uma forma cerebral e constróem-se personagens nos ensaios de mesa $e$, conseqüentemente, ignora-se a preparação corporal. 
O equívoco não é apenas desse determinado ator. Geralmente os atores gaúchos surgidos até meados da década de oitenta pensavam exatamente assim. Mais tarde, por outro lado, criou-se um preconceito muito grande entre os seguidores do chamado teatro corporal em relação a Stanislavski, até ele ser resgatado por Grotowski e Barba, resolvendo, pelo menos em parte, como se percebe aqui, esse histórico mal entendido.

Outro equívoco cometido pelo colega - e também não só por ele - é o fato de afirmar ser o teatro físico um 'teatro mais moderno' que exige uma preparação física maior, quando esse é o tipo de teatro almejado pelos 'rebeldes' que queriam, lá no final do século retrasado, dar uma espanada no empoeirado teatro naturalista e burguês em vigor na época. O "moderno" aqui citado não se refere ao período histórico Modernista, que por 'acaso', iniciou-se em meados do século XIX na Europa vindo abalar a cultura brasileira na Semana de 22, mas sim a uma contemporaneidade, uma "inovação".

Aliás, essa "inovação" chegou aos palcos gaúchos e criou seu espaço, tardiamente, por meados da década de 80. E, como aconteceu com os modernistas da década de 20, esses 'inovadores' foram alvo de um certo preconceito por parte de alguns atores do chamado teatro textual. Muitas vezes se ouvia que esse 'pessoal que pesquisa muito', leva doze meses ensaiando, o que poderia ter sido feito em apenas dois.

Outra questão - no mínimo curiosa - levantada nos depoimentos foi a necessidade de calma que alguns têm para se preparar. Pelo menos dois atores disseram precisar ficar quietos ou apenas conversando com os colegas. E ambos afirmaram sentir necessidade de pouco se movimentarem fisicamente antes de uma apresentação!

Realmente, cada um tem sua própria maneira de se concentrar, mas é difícil entender uma preparação corporal que passa mais pelo intelectual do que pelo físico; pela calma ao invés de pela movimentação, já que o corpo é formado de músculos que precisam ser exercitados, alongados e de articulações que precisam ser "azeitadas".

Porém, o ponto de equilíbrio a se perseguir é o que proporcione o melhor aproveitamento pessoal dentro de suas particularidades, partindo do princípio de que cada pessoa é única. 
Dentro desse pensamento, podemos entender e acreditar que cada ator, com suas diferenças e especificidades, consiga chegar a um resultado satisfatório de formas tão variadas e divergentes entre si.

\section{0 indivíduo e o grupo}

Uma das coisas que mais me chamou a atenção nas entrevistas foi a força que o grupo tem para influenciar na vontade dos indivíduos.

Muitos, quase todos, referem que seu aquecimento ou preparação varia conforme o grupo ou o trabalho que estão fazendo.

Alguns confessam uma certa dependência do diretor ou do seu assistente de direção para o incentivo na preparação corporal. O que me impressiona, por que o corpo do ator é, ou deveria ser, de competência do ator e não do diretor ou de quem quer que seja. Todo ator deveria estar ciente da imensa importância de cuidar do seu próprio corpo-instrumento.

Diferentemente dos que preferem realizar o aquecimento, ou parte dele, de uma forma coletiva, os atores que dependem explicitamente do consentimento ou do incentivo do diretor para realizar sua preparação corporal exercem seu ofício de forma temerária e irresponsável. Suas atitudes arriscam prejudicar não só a sua atuação como podem, na pior das hipóteses, levar a uma lesão que poderá arruinar sua carreira e sua vida. Isso sem falarmos na falta de iniciativa própria e no desleixo com o lado profissional, pois o momento de preparação corporal é um direito de todo o ator, além de um dever consigo próprio e com os demais colegas que também serão prejudicados com uma atuação fria que resultará, no mínimo, em um espetáculo sem energia

\section{3. $O$ instrumento dentro e fora do palco}

\footnotetext{
"Mais do que simplesmente mexer com o corpo fisicamente, as técnicas mexem (ou devem mexer) com o indivíduo como um todo." (Strazzacappa, 1998, p. 51)
}

Claro que há vários fatores que fazem com que nos descuidemos um pouco da saúde, mas acabamos pagando um preço alto com esses descuidos e temos que "correr atrás do prejuízo" depois. 
Alguns atores disseram ter começado a se preocupar com a sua saúde com o passar do tempo e terem optado por algumas mudanças para obterem uma saúde melhor.

Duas atrizes alegaram estarem afastadas temporariamente de seus treinamentos físicos por motivos que demandam muito tempo: gravidez recente ou finalização do mestrado.

Porém, aqui entra uma questão interessante a se levantar: o corpo de um ator treinado durante anos chega a um determinado ponto que, mesmo estando ele parado por certo tempo, consegue atingir novamente esse ponto de equilíbrio com mais facilidade do que um corpo destreinado, mesmo que jovem. Até porque, se essa pessoa treinou com certa intensidade ao longo de vários anos, adquiriu uma consciência corporal e faz uso diário dessa consciência corporal, então está tudo lá ainda, latente e pronto pra entrar em ação quando necessário.

Toda essa questão lembra o que Yoshi Oida relata sobre o que Zeami 3 disse sobre a flor (que significa, mais ou menos, encanto como uma qualidade particular de um artista no palco):

\begin{abstract}
"Zeami percebeu que em volta de 43 ou 44 anos sofremos uma mudança. (...) Reduzimos a expressão externa, mas mantemos a integridade de nossas ações. Não mais dependemos de nossa beleza física, mas o público ainda percebe alguma coisa delicada cujo movimento vem de dentro. Aí está novamente a "flor" verdadeira da arte do ator." (Oida, 2001, p. 162)
\end{abstract}

Em outras palavras, o trabalho do ator tende a melhorar a partir dos 40 anos. Isso ocorre se ele vem desenvolvendo e trabalhando antes, aos 20, 30 anos, numa espécie de acúmulo de experiência e treinamentos corporais que vão se modificando com o passar do tempo e com o tipo de exigência sofrida por ele.

Um outro ponto levantado nos remete ao que já havia falado anteriormente, sobre preconceito com os treinamentos.

Muito se pergunta sobre o porquê de tanto treinamento. Claro que existem muitos exageros e, quando o que é apresentado no palco não é tão maravilhoso, revolucionário e tão diferente do chamado teatro convencional, 
cabe o questionamento: 'para que serve tanto treinamento?'. Porém, como diz Barba,

"treinamento não garante resultados artísticos" (1995, p.244).

Barba explica como foi, junto com o seu grupo, compondo o treinamento:

\begin{abstract}
"No início, o treinamento foi acompanhado por uma série de exercícios tomados da pantomima, do balé, da ginástica, do esporte, da rítmica (enquanto teoria do ritmo), da ioga, das artes plásticas; exercícios que conhecíamos ou que tínhamos reconstruído. $O$ treinamento era coletivo, todos realizavam os mesmo exercícios ao mesmo tempo e do mesmo modo. Com o correr do tempo, nos demos conta de que o ritmo é diferente de indivíduo para indivíduo.

(...) Desde então, o treinamento passou a se basear neste ritmo, foi se personalizando, tornando-se individual. (...) No nosso teatro, não existem professores, não existem pedagogos, são os atores que elaboram o próprio treinamento. Os companheiros mais velhos dão conselhos, colocam a sua experiência a serviço dos mais jovens.

Assistido por um dos mais velhos, o jovem começa a assimilar uma série de determinados exercícios, que, uma vez dominados, Ihes permite individualizálos, isto é, torná-los pessoais segundo o próprio ritmo e o próprio modo de abordar o trabalho, isto é, a própria motivação." (1991, ps 53-54)
\end{abstract}

Esta forma de treinamento remete a Commedia Dell'Arte em que os papéis e os exercícios passavam dos mais velhos para os mais jovens. Porém, não se sabe (e eu duvido, até por motivos históricos) se lá existia esse respeito aos ritmos individuais como nos experimentos de Barba e sua trupe.

Treinamento funciona como um meio para se obter um aprimoramento artístico e pessoal, nunca como um fim em si. Nunca o produto final do trabalho, como nos diz Márcia Strazzacappa:

"é comum depararmos com atores que transformam o treinamento técnico no objetivo do trabalho artístico do ator" (2004, p.71-72).

E, assim, algumas vezes o que se leva ao público são meras demonstrações técnicas que acabam desacreditando o verdadeiro treinamento corporal, diminuindo a importância de um bom trabalho corporal preparatório e alimentando ainda mais o preconceito em relação ao teatro mais físico e menos verbal. 


\section{Conscientização ou lesão}

Partindo da já citada Nostalgia instaurada no teatro e da evolução das técnicas corporais iniciadas pela dança moderna a partir do final do século XIX, o corpo e seus movimentos viraram objeto de estudo e exploração dentro e fora do palco.

Como objeto de exploração, o corpo passou a ser testado sob todas as formas e maneiras. Com o passar do tempo, a exacerbação da utilização de técnicas corporais sem um aprofundamento teórico ou uma maior conscientização corporal, levaram atores a adquirirem lesões, fraturas, contusões, distensões.

O que vemos nos depoimentos é uma comprovação de que tanto o exagero quanto a falta de conscientização podem levar a graves conseqüências e colocar em risco não só o trabalho como a própria vida dos atores.

Quase todos relataram alguma lesão ocorrida por exagero no treinamento.

Muitos tiveram problemas vocais por não terem noção de como cuidar e trabalhar a voz por não dominarem a técnica.

Começamos a observar em Porto Alegre, a partir da década de 80, uma super valorização das técnicas corporais, ao contrário do que ocorria anteriormente. E essa corrida às técnicas corporais, infelizmente, nem sempre foi feita de uma forma embasada, aprofundada. Atualmente, conforme a pesquisa, estamos tentando encontrar um ponto de equilíbrio entre essas duas forças opostas. Os traumas causados pelas lesões levaram a uma busca maior pela conscientização corporal, como observa Strazzacappa:

"Atores, bailarinos, cantores e músicos vítimas constantes de contusões, traumas e lesões, começaram a prestar mais atenção no próprio corpo e a buscar linhas de trabalho corporais, normalmente conhecidas no Brasil como "técnicas alternativas" (1999, p.168).

Entre os bailarinos é crescente o interesse pelas técnicas corporais que englobam uma nova disciplina, dita de emergência, chamada de Educação Somática. 
As disciplinas somáticas são de origem ocidental, surgiram no início e ao longo do século $\mathrm{XX}$ e se constituíram como disciplina e área de estudo durante a década de 80

\footnotetext{
"Novo campo de estudo, a educação somática engloba uma diversidade de conhecimentos onde os domínios sensoriais, cognitivo, motor, afetivo e espiritual se misturam com ênfases diferentes." (Fortin, 1999, p.40)
}

Técnicas corporais como os métodos desenvolvidos por F. Matias Alexander, Moshe Feldenkrais, Imgard Bartenieff e também pelos brasileiros Klaus Vianna e Ivaldo Bertazzo, entre outros, visam à melhora da técnica, a prevenção e cura de lesões e o desenvolvimento das capacidades expressivas,

"ajudando a dança a ultrapassar velhos paradigmas de um corpo
perfeito, moldado e idealizado frente à cena, mas extremamente
massacrado e escravizado no seu cotidiano". (Weber, 2003, p. 205)

O mais importante na Educação Somática é que suas técnicas abordam a unicidade corpo-mente, a consciência corporal e percepção proprioceptiva. $O$ praticante (atorbailarino) se torna agente de seu próprio aprendizado de uma forma consciente e diminuindo assim, em muito, as lesões, os traumas muito freqüentes nas práticas mecânicas ou feitas, como se diz por aqui, "a la louca", de qualquer jeito. Isso é muito comum, infelizmente, em alguns cursos de final de semana; em grupos iniciantes em que um integrante leu num livro tal exercício e passa para o restante do grupo ou até em grupos profissionais que fizeram curso com um ex-aluno-de-um-cara-que-viu-umademonstraçãodo-grupo-do-Barba e que resolvem colocar em prática sem qualquer preparo.

Pude perceber nas entrevistas que a atividade corporal mais citada foi a Yoga. Sabese que existem várias vertentes ou subvertentes da Yoga. Porém, o que chama a atenção dos seus praticantes, em geral, é a possibilidade de uma prática que não ofereça riscos e que, ao mesmo tempo, auxilie na conscientização corporal, como as disciplinas somáticas.

Outras práticas orientais milenares como o Kung-Fu (Tai-Chi-Chuan e Shao-Lin), bem como a brasileiríssima Capoeira, também podem fornecer a mesma conscientização e prevenção. Existe, portanto, uma grande variedade de atividades a se escolher. $\mathrm{O}$ importante, como acontece no bom treinamento, 
é que o ritmo individual seja respeitado. Não adianta nada continuarmos indo ao sabor do modismo e praticarmos atividades corporais que nada tenham a ver com o nosso corpo e o nosso ritmo interno. Às vezes, uma bela caminhada diária pode nos dar tanta consciência corporal quanto uma atividade mais elaborada. O que vale é não ficarmos totalmente parados nem nos lesionarmos por excesso.

O título deste artigo, em forma de pergunta, é mais uma provocação do que uma indagação de fato.

Minhas impressões iniciais de que existe uma variada gama de atores com práticas corporais diferentes mudou pouco.

Notei, pelas respostas recebidas, que os atores gaúchos vêm se preocupando mais com a saúde do seu corpo, sim. Em muitos casos, porém, a preocupação com a saúde veio após um trauma, uma lesão.

Percebi, ainda, que falta um embasamento teórico muito grande ou de uma formação mais consistente. Usa-se muito o 'achismo' no treinamento corporal: 'ah, acho que esse exercício é bom para...' ou 'ouvi falar que esse outro é o ideal para... '. Vejo poucos atores realmente estudando, pesquisando e trocando experiências de uma forma responsável.

Como passamos, rapidamente, de um teatro psicológico, que negava 0 corpo, para um teatro corporal que negava o texto (e essa passagem ocorreu sem questionamentos, sem embasamento teórico) a tendência, agora, é que o pêndulo comece a perder força e velocidade chegando a um meio-termo. Está ocorrendo agora uma procura por técnicas alternativas que trabalhem o corpo como um todo, sem separações de físico e mente. Isso abre espaço para que surjam atores mais conscientes, mais questionadores e mais criativos.

Afinal de contas, em que século se encontra o corpo do ator gaúcho?

Não temos, a meu ver, um só corpo: o corpo do ator gaúcho. Pude perceber que temos, pelo menos, 3 corpos que atuam, de forma simultânea, nos últimos 3 séculos.

Explico-me: existem os corpos que ainda ficaram lá no século XIX e preocupam-se apenas em estudar e decorar seus textos, passando e repassando cenas sob a orientação de um diretor que faz todas as marcações, 
não deixando espaço para questionamentos. Muito menos para um corpo ativo e expressivo.

Há também uns poucos que ainda estão se debatendo no século $X X$. Exaustos, suados, explorando todas as possibilidades que esse corpo pode dar, mas esquecidos de que esse corpo precisa ir à cena. Que treinamento não é arte em si, e sim, um meio para chegar até ela.

Por fim, há alguns outros corpos que estão chegando ao século XXI depois de terem passado pelos outros dois séculos e sentido, na própria pele, que treinamento é importante sim, mas com saúde e conscientização corporal. Dentro e fora do palco.

Esse é o corpo do ator criador, o corpo expressivo, o corpo para quem pensa e atua. Um corpo agente de sua própria arte. 


\section{NOTAS:}

1 Nostalgia é o título de um dos capítulos de 'A Arte Secreta do Ator' (1995), onde Barba e Savarese falam sobre como começou esta redescoberta do teatro corporal.

2 Sempre que aparecer aqui a palavra ator, leiase ator-bailarino ou, ainda, artista cênico.

3 Motokiyo Zeami (1363-1443) - mestre japonês responsável pela criação do Teatro Nô.

\section{REFERÊNCIAS BIBLIOGRÁFICAS:}

BARBA, Eugenio. Além das Ilhas Flutuantes. Campinas: Editora Hucitec/Editora da Unicamp, 1991.

BARBA, Eugenio. A Canoa de Papel. Campinas: Editora Hucitec/Editora da Unicamp, 1994.

BARBA, Eugenio e SAVARESE, Nicola. A Arte Secreta do Ator. Campinas: Editora

Hucitec/Editora da Unicamp, 1995.

FORTIN, Sylvie. Educação somática: Novo ingrediente da formação prática em dança.

Cadernos do GIPE-CIT, Salvador, n. 2, p. 40-55, fev. 1999.

OIDA, Yoshi e MARSHALL, Lorna. O Ator Invisível. São Paulo: Beca Produções Culturais, 2001.

PRÓCHNO, Caio César Souza Camargo. Corpo do Ator: metamorfoses, simulacros. São Paulo: FAPESP: Anhablume, 1999.

ROUBINE, Jean-Jacques. A Arte do Ator. Rio de Janeiro: Jorge Zahar Editor Ltda, 1987. STRAZZACAPPA, Márcia. As Técnicas Corporais e a Cena.In: GREINER, Christine; BIÃO, Armindo (org). Etnocenologia - Textos Selecionados. São Paulo: Annablume, 1999.

STRAZZACAPPA, Márcia. Técnicas Corpóreas. Revista do Lume, Campinas, n.1, p. 45-51, outubro, 1998.

STRAZZACAPPA, Márcia. Sobre Todas e Nenhuma. Cena, Porto Alegre, n.3, p. 67-75, outubro, 2004.

WEBER, Suzane. A Educação Somática como Fonte de Conhecimento para a Dança. Anais do III Congresso de Pesquisa e Pós-Graduação em Artes Cênicas (Memória ABRACE VII), Florianópolis, p. 204-205, 2003. 